\title{
ACOLHIMENTO COM CLASSIFICAÇÃO DE RISCO: QUE LUGAR É ESSE?
}

Hosana Ferreira Rates ${ }^{1}$, Marilia Alves ${ }^{2}$, Ricardo Bezerra Cavalcante ${ }^{3}$

Objetivo: conhecer o Acolhimento com Classificação de Risco (ACCR) como lugar próprio e espaços criados pelos sujeitos. Metodologia: estudo de caso de abordagem qualitativa. Realizaram-se entrevistas semiestruturadas com 20 enfermeiros e observação assistemática em uma Unidade de Pronto Atendimento, em 2015. Os dados foram submetidos à Análise de Conteúdo Temática. Resultados: o ACCR vai além de um ambiente ou uma postura adotada pelos profissionais, é um lugar próprio, pois é delimitado por normatizações, regras previamente estabelecidas que intentam circunscrever os sujeitos e isolá-los. Além disso, nesse lugar próprio, os espaços são delimitados a partir do caminhar que cada profissional e usuário empreendem no âmbito do ACCR. Cada qual tem o seu fazer, a sua intencionalidade, a sua vivência estimulada por situações que circunstanciam aquele ambiente. Conclusão: o Acolhimento como lugar próprio-espaço deve ser considerado, visando intervenções sobre a sua realidade.

Descritores: Enfermagem em emergência; Triagem; Serviços médicos de emergência

\section{USER EMBRACEMENT WITH RISC CLASSIFICATION: WHAT IS THIS PLACE?}

Objective: to know the User embracement with Risk Classification (ACCR) as the proper place and spaces created by the subjects. Methodology: the type is a case qualitative study. There were semi-structured interviews with 20 nurses and no systematic observation in an Emergency Unit, in 2015. The data were submitted to Thematic Content Analysis. Results: it was found that the ACCR goes beyond an environment or posture adopted by professionals, is a proper place it is delimited by norms, rules, previously established that attempt to circumscribe the subject and isolate them. Moreover, in this own place, the spaces are delimited from the walk that every professional and user undertaking under the Emergency Triage. Each one has its making, its intentionality, its experience stimulated by situations which circumstance that environment. Conclusion: the conformation of the triage while own place-space should be considered targeting interventions on their reality.

Descriptors: Emergency nursing; Triage; Emergency medical services

\section{ACOGIMIENTO CON CALIFICACIÓN DE RIESGO: ¿QUÉ ES ESTE LUGAR?}

Objetivo: conocer el Acogimiento con Calificación de Riesgo como el lugar proprio y espacios creados por los sujetos. Metodología: estudio de caso cualitativo. Hubo entrevistas semiestructuradas con 20 (veinte) enfermeras y observación no sistemática en un servicio de emergencia en el año 2015. Los datos fueron sometidos a Análisis de Contenido Temático. Resultados: el Acogimiento va más allá de un ambiente o una postura adoptada por los profesionales, es un lugar apropiado, es delimitada por las normas, las reglas establecidas con anterioridad que el intento de circunscribir el sujeto y aislarlos. Por otra parte, este lugar en sí, los espacios están limitados por el caminar de el profesional y usuario en el Acogimiento. Cada uno tiene su hacen, su intencionalidad, su experiencia estimulada por el situaciones que circunstancian ese entorno. Conclusión: acogimiento como el lugar propio en el espacio debe ser considerado con el fin de intervenir sobre su realidad.

Descriptores: Enfermería de urgencias; Triaje; Servicios médicos de urgencia

'Enfermeira. Mestre em Enfermagem. Professora Universidade Federal de São João Del Rei.

Enfermeira. Doutora em Enfermagem. Professor Titular Universidade Federal de Minas Gerais.

${ }^{3}$ Enfermeiro. Doutor em Ciência da Informação. Professor Adjunto Universidade Federal São João Del Rei. 


\section{INTRODUÇÃO}

No Brasil, o Acolhimento com Classificação de Risco (ACCR) tem apresentado dificuldades de implantação e encontra desafios para sua institucionalização. A estrutura física desses serviços necessita de readequações ${ }^{(1,2)}$; os profissionais não se sentem capacitados, bem como apresentam sofrimentos diante das tensões que ali vivenciam $^{(3)}$. Ressaltam-se ainda a inadequada referência e contra referência ocasionada pela insuficiente implementação da Política Nacional de Atenção às Urgências ${ }^{(1,2)}$.

Intervir sobre essa realidade complexa é uma necessidade. Entretanto, é preciso conhecê-la além do que realmente aparenta, não apenas como uma estrutura física ou uma postura inerente à maneira de acolher de cada profissional. Conhecer o ACCR como um lugar próprio e os espaços inscritos pelos sujeitos nesse lugar é um avanço necessário, pois é nesse lugar próprio que o enfermeiro se vê desafiado e empreende seus movimentos; delimitando o seu espaço, escapa da norma e constrói o seu cotidiano de trabalho por meio de seu próprio fazer. Lugar próprio e espaço são interdependentes e conformam o cotidiano. Um lugar é a ordem segundo a qual se distribuem elementos nas relações de coexistência e impera a lei do "próprio". Isto é, os elementos considerados se acham uns ao lado dos outros, cada um situado num lugar "próprio" e distinto. Já o espaço é a delimitação dos movimentos realizados pelos sujeitos, onde as relações de poder e produção de saber se manifestam. $O$ espaço é o lugar praticado, o jeito de fazer de cada sujeito e suas interações ${ }^{(3)}$.

Assim, propos-se as seguintes questões norteadoras: Como se constitui o ACCR como lugar próprio? Como são os espaços criados pelos sujeitos no ACCR? Enfim, este estudo buscou conhecer o ACCR como lugar próprio e os espaços criados pelos sujeitos.

\section{METODOLOGIA}

Realizou-se um estudo de caso com abordagem qualitativa utilizando-se o referencial teórico de Certeau ${ }^{(4)}$ sobre "cotidiano", sobretudo seus conceitos de lugar próprio e espaço.

O cenário escolhido foi uma Unidade de Pronto Atendimento (UPA) de um município de médio porte do Centro-Oeste mineiro. O município é sede da Superintendência Regional de Saúde. É referência de saúde para 54 municípios em seu entorno. A UPA foi construída em 2013, sendo considerada de Porte III, que estabelece no mínimo 15 leitos de observação com capacidade de atender até 350 pacientes por dia em uma população na área de abrangência de 200 mil a 300 mil habitantes. A opção por realizar o estudo nessa unidade se justificou pela facilidade de acesso dos pesquisadores e por ser a única UPA do município em foco. O ACCR é realizado em dois consultórios construídos para tal fim e se situam próximos à recepção. Atualmente, a UPA possui 22 enfermeiros que realizam o ACCR no período diurno e noturno, sendo que esses foram os potenciais participantes da pesquisa. Entretanto, um enfermeiro recusou-se a participar do estudo e outro se encontrava de férias. Assim, participaram do estudo 20 enfermeiros.

A coleta de dados foi realizada entre os meses de janeiro e fevereiro de 2015, por meio de entrevistas semiestruturadas com os enfermeiros e observação assistemática de seu cotidiano de trabalho. Cada enfermeiro recebeu um código para garantir seu anonimato (letra $E=$ Enfermeiro e o número 1 a 20 para as entrevistas). As entrevistas tiveram uma duração média de 40 minutos e continham questões relacionadas ao perfil do respondente, sobre o processo de trabalho desenvolvido no ACCR e as práticas cotidianas utilizando o protocolo de Manchester de classificação de risco.

O registro das observações (NO: notas de observação) foi realizado em um diário de campo. Buscou-se observar o cotidiano de trabalho dos profissionais no ACCR e suas relações com os usuários atendidos. As observações ocorreram durante o período de realização das entrevistas e em caráter complementar. Os dados coletados foram submetidos à Análise de Conteúdo Temática(5), que se processou da seguinte forma: na la a fase, realizou-se a Pré-análise ou Leitura flutuante: o primeiro contato com os documentos consistiu em analisar e conhecer o texto; realizou-se a preparação do material: as notas da observação registradas no diário de campo e as transcrições das entrevistas constituíram o corpus da pesquisa. Na 2a fase, realizou-se a exploração do material, sua codificação. Foram extraídas as unidades de registro, os núcleos de sentido, as unidades de contexto e por fim as categorias temáticas. $\mathrm{Na} 3$ a fase, os resultados foram tratados de maneira a serem significantes e válidos. A análise das entrevistas foi enriquecida com o material das observações, articulando dados empíricos e referenciais teóricos, buscando responder às questões da pesquisa.

A pesquisa foi aprovada pelo Comitê de Ética em Pesquisa com Seres Humanos da Universidade Federal de Minas Gerais, sob parecer no 799.271 e CAAE 33125014.0.0000.5149.

\section{RESULTADOS}

A partir da análise, foram construidas as seguintes categorias: O Acolhimento com Classificação de Risco como um lugar próprio; Os espaços criados no Acolhimento com Classificação de Risco: a prática do lugar, descritas a seguir. 
O Acolhimento com Classificação de Risco como um lugar próprio

Verificou-se que o cenário envolvendo o ACCR constituise como um lugar impregnado por símbolos que remontam à sua história e finalidade. A disposição do cenário, as cores de classificação e a nomenclatura dada aos profissionais retratam a finalidade do serviço disponibilizado: $A$ primeira impressão ao chegar à UPA em uma segunda-feira, às 7 horas da manhã, foi de admiração. Um prédio de construção nova [...] uma recepção ampla, com as cadeiras demarcadas da cor específica para os pacientes classificados como azul e verde. [...] um painel eletrônico com o nome dos médicos emergencistas, do enfermeiro classificador e do enfermeiro coordenador. Haviam também dois consultórios dos enfermeiros classificadores (NO).

O ACCR como lugar também possui instrumentos de trabalho, normatizações, regras de conduta a serem seguidas pelos profissionais: [...] os formulários de classificação e o manual do Sistema Manchester de Classificação de Risco (deve ser consultado quando houver dúvidas sobre a normalização) (NO); Os TRIUS (triagem em unidades de saúde) também estavam disponiveis e em funcionamento. São computadores com o software estadual do Protocolo de Manchester e trazem acoplados termômetro auricular e oximetro(NO). Eu tenho o computador que tem os programas do governo entre ele o SIS (Sistema Integrado de Saúde), e o Manchester propriamente dito [...] o oximetro, o termômetro e o aparelho de pressão (E13); Eu preciso do liuro que tem os protocolos com os discriminadores, os fluxogramas completos e quando o TRIUS está inoperante então nós temos que usar outro instrumento, que é a Classificação manual (E2).

Também, foi constatada a existência de um fluxo normatizado, a ser percorrido pelos pacientes e a ser operacionalizado pelos profissionais nesse lugar próprio: O recepcionista questiona sobre a demanda do paciente visando direcioná-lo a uma das especialidades preexistentes no SIS (Sistema Integrado de Saúde) e encaminhá-lo ao ACCR [...] (NO); O enfermeiro chama o paciente [...], em seguida abre o software do Protocolo de Manchester [...]. Na sequência passa para a página de triagem, onde pergunta ao paciente o motivo pelo qual procurou o serviço[...] e seleciona - fluxograma da queixa principal e após a classificação encaminha para o médico ou assistente social (NO). Após o paciente passar pela recepção, ele vem para a classificação e utilizamos o TRIUS, que é o computador com o programa do Protocolo de Manchester da SES [Secretaria Estadual de Saúde]. Aqui tem particularidade de ter o SIS, que é um sistema de informação municipal em que a gente alimenta concomitante com a classificação feita pelo TRIUS.
Dependendo da classificação, o paciente vai para a sala vermelha ou amarela ou fica aguardando o médico. No caso de paciente verde ou azul para ser encaminhado para atenção básica, ele passa pela assistente social (E3).

\section{Os espaços criados no Acolhimento com Classificação de Risco: a prática do lugar}

Apesar de o ACCR ter características que o delimitam como um lugar próprio (normatizado e regimentado), também são criados espaços a partir dos movimentos dos sujeitos (profissionais e usuários) ali inseridos e de seus relacionamentos. Assim, o ACCR é um lugar praticado que vai além das normas e regras estabelecidas; existem, nesses espaços do ACCR, maneiras próprias de cuidar e fazer saúde.

Primeiramente, verificamos que os enfermeiros classificadores executavam suas atividades concentradas, predominantemente, no interior do consultório, a partir de um fazer solitário, repleto de expressões corporais que denotavam sentimentos de angústia e impotência diante de situações emergentes. Os enfermeiros ficavam a todo otempo dentro do consultório, realizando o ACCR, interrompiam o atendimento somente para realizar suas necessidades fisiológicas (NO); Uma enfermeira durante o atendimento a um idoso demonstrou-se angustiada, frustrada, pois não conseguia encaixar o paciente em nenhum fluxograma de atendimento. A necessidade daquele usuário era outra. Já estava há dias sem comer e perambulando pelas ruas, encontrou na UPA uma porta de entrada para resolver seu problema, mas sem solução (NO).

O consultório para esses profissionais representava um refúgio diante da alta demanda por classificação e diante das insatisfações verbalizadas por pacientes e acompanhantes. Vários [pacientes] expressavam a indignação verbalizando que já estavam esperando há muito tempo para serem atendidos. Alguns enfermeiros pareciam se 'proteger' dentro dos consultórios e saiam às vezes para chamar os pacientes. Eles demostravam sentimento de angústia diante da impotência relacionada ao sistema de saúde ineficiente e aos colegas de todos os niveis de atenção que não se implicavam com o trabalho. Suspiravam fundo e verbalizavam dizendo que era muito difícil estar ali (NO); A sensação que a gente tem é que é um trabalho sem fim, é um saco sem fundo [..] Às vezes a gente sente medo... fica muito exposto todo dia. Eu acho se as coisas funcionassem da forma que precisam funcionar, o atendimento médico ser mais rápido, talvez tudo isso seria minimizado [...] a demanda seria menor, a gente iria trabalhar melhor! (E3).

Outra constatação foi a forma de acolher dos enfermeiros por meio de uma triagem rápida voltada para a queixa e sua localização no corpo e não para questões de ordem 
social, emocional ou outras. [...] o diálogo se resumia ao questionamento inicial sobre o que estava sentindo e onde. O paciente apenas respondia e não havia qualquer outro diálogo. A classificação era realizada e partia-se para o próximo paciente (NO); [...] é uma pequena entrevista, que pergunto qual é a queixa principal, porque veio aqui? E alguns parâmetros que a gente é obrigada a seguir [...] é rapidinho, cê tem que triar em três minutos no máximo [...] (El).

Os profissionais também se movimentam no sentido de promover interações no cotidiano de trabalho. Criam espaços que se intercruzam com os demais. São construidos a partir do diálogo multiprofissional que se origina da necessidade de definição de condutas, da organização do fluxo de atendimentos e priorização dos pacientes: [...] ele [funcionário da recepção] acaba me direcionando paciente que realmente precisava ter uma priorização [...] (E2); [...] não é incomum ouvir ele [o usuário] conversar às vezes com o rapaz da portaria ou com algum técnico, 'ah você tem que voltar lá e a enfermeira vai te dar cor [...] (E3); [...] em alguns casos que não são pra UPA, a gente passa pra assistente social pra ela tá direcionando (E19); [...] você tem que ir ali conversar com o médico para trocar uma ideia com ele pra ver como que vai encaminhar o paciente (Ell). Os pacientes inseridos nesse lugar, também criam seus espaços. Apesar de serem, em sua maioria, classificados como verde e azul, movimentam-se a partir de um caminhar próprio direcionado à UPA: [...] em torno de 80 , 90\% das pessoas que vem aqui é de atenção básica [...] a gente brinca que é um saco sem fundo, não tem fim [...] é um gargalo que vem da atenção básica (E3); [...] maioria inclusive vem aqui pra consultinha [...] Aqueles negócios que tá acontecendo há três meses e ele vem aqui pra resolver mais rápido [...] (E8).

Este caminhar promovido pelos usuários é o seu jeito próprio criado para escapar das situações que o pressionam, conforme destacado a seguir. [...] ele [usuário] vai no posto de saúde com a queixa, às vezes nem é ouvido muito bem lá e já encaminhado pra cá, pra UPA, né!? (Ell); A demanda aqui é muito grande por não ter hospital, só ter UPA [...] (E5); [...] nós ainda recebemos o azul aqui, porque nós não temos unidades de referência pra tá encaminhando esse paciente [...] (El7).

\section{DISCUSSÃO}

A partir dos resultados verificados, é possível elencar algumas características do ACCR como um lugar próprio. Primeiro, há uma lógica organizativa e estruturada voltada para as demandas de urgência e emergência. O cenário, os materiais e os fluxos foram estruturados para receber uma clientela que tenha as suas demandas ouvidas e solucionadas. Das observações, foi possivel depreender que o serviço não foi criado de qualquer forma, pelo improviso, ou transformado a partir de outra finalidade. Pelo contrário, foi arquitetado geometricamente para se conformar como um ponto da rede assistencial cuja finalidade é atender às demandas assistenciais por urgência/emergência. É preciso reconhecer este avanço no cenário observado, pois é muito comum verificar no país a criação de serviços de urgência/ emergência adaptados, com pouca estrutura e sem uma lógica organizativa, prejudiciais ao atendimento que se deseja implementar ${ }^{(6,7)}$.

Ainda, reconhece-se que há uma normatização direcionadora do trabalho desenvolvido pelos profissionais. O Protocolo de Manchester com seus fluxogramas de atendimento e os sistemas de informação (manuais, software, SIS) são elementos que remetem a esse fazer normatizado com vistas à padronização e ao alinhamento com uma política definida a priori ${ }^{(8)}$.

Todas essas características desse lugar próprio apontam para a existência de um sistema cultural estabelecido por políticas, leis, regras que intentam circunscrever os sujeitos nesse lugar, cabendo-lhes o consumo desse sistema cultural( ${ }^{(4)}$. Assim, espera-se que os símbolos contidos nesse lugar e suas normatizações sejam compreendidos e respeitados como a lei do lugar, o sistema de condutas que ali se aprova e se permite.

Entretanto há um fazer do enfermeiro que rompe com a lógica estruturada e normatizada do ACCR como um lugar apenas. Empreende-se neste cenário os movimentos que delimitam o seu espaço, é a prática de um lugar, estimulada por situações circunstanciais (pressões, alta demanda, tempo). O fazer do enfermeiro, nesse espaço criado, se adapta, se (re)inventa. Assim, a proposta é de que o ACCR não seja compreendido apenas como um lugar próprio, aquele do protocolo e da normatização, representado por um consultório onde se faz uma avaliação dos riscos e prioridades, mas é, ao mesmo tempo, um espaço repleto de movimentos que devem ser considerados, visando o acolhimento e a escuta qualificada. Nessa ótica, o ACCR é um lugar-espaço, onde o "acolher" ganha outra importância, o vínculo, o estabelecimento de uma escuta que proporciona a responsabilização pelo problema do outro no ensejo por resolvê-lo ou por buscar possibilidades ${ }^{(9)}$. Cabe a necessidade de empoderá-lo nessa direção para fazer valer essa potencialidade.

Assim, apesar da organização do fluxo de atendimento nesse lugar estar centrado num modelo biologicista que valoriza o saber especializado sobre o processo patológico(10), cada profissional empreende um movimento próprio, cria seus espaços, com vistas a dar conta da realidade. Esses espaços se inter-relacionam e contribuem para a organização do fluxo de atendimento que depende dessas interações, onde cada profissional, em sua função, executa suas atividades, mas há uma continuidade no trabalho do outro. 
É necessário fortalecer a comunicação entre os profissionais com vistas a favorecer o cuidado na urgência uma vez que o trabalho em equipe origina-se a partir da necessidade de promover a qualidade dos serviços em saúde, de maneira a atender eficientemente às demandas do paciente(11).

Assim como os profissionais, a população também institui o seu próprio fazer, é um caminhar próprio na rede assistencial, inventa o seu espaço e busca na UPA uma oportunidade de ter os seus problemas de saúde resolvidos. A procura do serviço de urgência relacionada a sinais e sintomas não urgentes (classificação verde e azul) é uma constante no Brasil ( $45 \%$ e $62,4 \%$ dos atendimentos) e também nos Estados Unidos (37\% das classificações) $)^{(12)}$. Esse caminhar por assistência na urgência é decorrente da falta de resolutividade nos níveis básicos da rede de saúde, da falta e/ ou demora no apoio diagnóstico, da demora de consulta em especialidades médicas, bem como da ausência de médico na unidade básica ${ }^{(13)}$

Esta situação circunstancial coloca de um lado usuários que demandam a sua necessidade de saúde/doença/cuidado e de outro, profissionais e o próprio sistema organizacional (lógica organizativa do sistema - o lugar próprio versus lógica de demanda do usuário - o espaço criado). O espaço é vivo, não há de ser apenas um lugar cuja ordem se estabelece e fixa a aceitação de um sistema cultural a ser consumido(4).
Desta feita, o paciente, que também compõe as cenas desse lugar, movimenta-se e exige cuidado, almeja a resolução de seu problema e empreende os seus movimentos repletos de intencionalidades.

Enfim, admite-se como limitação neste estudo a impossibilidade de generalizações. A realidade encontrada é característica do contexto estudado, entretanto, pode ser utilizada para o norteamento de estudos futuros.

\section{CONSIDERAÇÕES FINAIS}

O ACCR vai além de um ambiente ou uma postura adotada pelos profissionais, é um lugar próprio, pois é delimitado por normatizações, regras previamente estabelecidas que intentam circunscrever os sujeitos e isolá-los. Além disso, nesse lugar próprio, os espaços são delimitados a partir do caminhar que cada profissional e usuário empreendem no âmbito do ACCR. Cada qual tem o seu fazer, a sua intencionalidade, a sua vivência estimulada por situações que circunstaciam aquele ambiente. Estes espaços devem ser considerados com vistas a intervir sobre a realidade que se estabelece no ACCR; não se pode intervir sobre as problemáticas ali existentes apenas com o intuito de adequar o ACCR à norma. As subjetividades, as interações e os movimentos inerentes aos sujeitos ali presentes vivificam aquele lugar e devem contribuir para o seu aperfeiçoamento.

\section{REFERÊNCIAS}

1. Vituri DW, Inoue KC, Bellucci Junior JA, Oliveira CA, Rossi RM, Matsuda LM. Acolhimento com classificação de risco em hospitais de ensino: avaliação da estrutura, processo e resultado. Rev. Latino-Am. Enfermagem. 2013: 21(5): [9 telas]

2. Versa GLGS, Vituri DW, Buriola AA, Oliveira CA, Matsuda LM. Avaliação do ACCR em serviços de emergência hospitalar. Rev Gaúcha Enferm. 2014; 35(3): $21-8$

3. Freitas FFB, Matos GSS, Cavalcante AC, Pinheiro MBGN, Sousa MNA. O papel do enfermeiro no serviço de acolhimento e classificação de risco no setor de urgência e emergência Revista Interdisciplinar em Saúde, 2015; 02 (3): $314-33$

4. Certeau MA. Invenção do cotidiano: artes de fazer. 15 ed. Petrópolis: Vozes; 2014

5. Bardin L. Análise de conteúdo. Lisboa: Ediçōes 70; 2011.

6. Brasil. Ministério da Saúde. Sistema de Legislação da Saúde. Portaria no 354. de 10 de março de 2014. Publica a proposta de Projeto de Resolução "Boas Práticas para Organização e Funcionamento de Serviços de Urgência e Emergência".

7. Fernandes L, Göttems L. Humanização e ambiência na clinica médica do hospital de base do Distrito Federal. Gestão e Saúde. 2013; 4(3): 38-52.
8. Pinto Júnior D, Salgado PO, Chianca TC. Predictive validity of the Manchester Triage System: evaluation of outcomes of patients admitted to an emergency department. Rev. Latino-Am. Enfermagem. 2012; 20(6): $1041-7$

9. Raimundo J S, Cadete, M M M. Escuta qualificada e gestão social entre os profissionais de saúde. Acta Paul Enferm. 2012; 25(2): 61-7.

10. Costa RHS, Couto RO, Silva RAR. Prática clínica do enfermeiro na estratégia de Saúde da Familia. Saúde (Santa Maria). 2015: 41(2): 09-18.

11.Oliveira AM, Lemes AM, Machado CR, Silva FL, Souza MF. Relação entre enfermeiros e médicos em hospital escola: a perspectiva dos médicos. Rev. Bras. Saude Mater. Infant. 2010: 10 (2): 433-9.

12. Santos DS. O cotidiano de um serviço de urgência e emergência nos discursos de usuários e trabalhadores. Escola de Enfermagem, Universidade Federal de Minas Gerais (UFMG), Belo Horizonte, 2015.

13. Caveião C. Hey AP. Montelezi JH. Barros APMM. Sordi JA, Santos SC. Desafios ao enfermeiro na implantação da classificação de risco em unidade mista. Rev Enferm UFSM. 2014: 4(1): 189-96. 